\title{
Цивільна безпека
}

\author{
В. А. Глива ${ }^{1}$, О. В. Панова ${ }^{2}$, О. М. Тихенко ${ }^{1}$, Л. О. Левченко ${ }^{3}$ В. П. Колумбет ${ }^{3}$ \\ ${ }^{1}$ Національний авіаційний університет, Київ, Україна \\ ${ }^{2}$ Київський національний університет будівництва і архітектури, Київ, Україна \\ ${ }^{3}$ Національний технічний університет України «Київський політехнічний інститут \\ імені Ігоря Сікорського», Київ, Україна
}

\section{ДОСЛІДЖЕННЯ АМПЛІТУДНО-ЧАСТОТНИХ ЗАЛЕЖНОСТЕЙ ЗАХИСНИХ ВЛАСТИВОСТЕЙ МАГНІТНИХ ЕКРАНІВ НА ОСНОВІ АМОРФНИХ СПЛАВІВ}

\begin{abstract}
Анотація. Сучасні методи екранування допускають використання найбільш придатних металевих матеріалів для одночасного вирішення декількох задач для захисту працюючих та електромагнітної сумісності технічного обладнання. Одним з таких ефективних металевих матеріалів вважають аморфні магнітом'які сплави. Предмет дослідження даної роботи - визначення захисних властивостей аморфного магнітом'якого сплаву при різних значеннях частотних та амплітудних характеристик в залежності від зміни товщини стрічки матеріалу. Досліджено магнітні властивості пермалою від різної частоти екранованого поля з різним відсотковим вмістом нікелю та різною товщиною захисного металевого матеріалу; залежності коефіцієнта екранування магнітом'яких аморфних сплавів від індукції зовнішнього магнітного поля; коефіцієнти екранування аморфного магнітом'якого сплаву різної товщини та різного відсоткового вмісту кобальту від змінних значень амплітуди; магнітооброблений стан та вихідний стан (недоліки та переваги для конкретних умов використання при захисті та економічних вимог); залежності магнітної проникності магнітом'якого аморфного сплаву від різних значень частоти та амплітуди. Мета роботи - визначення коефіцієнтів екранування захисних аморфних магнітом'яких сплавів від амплітудно-частотних характеристик екранованого магнітного поля та обгрунтування ефективності використання таких матеріалів та надання конкретних рекомендацій щодо захисту від електромагнітних полів та випромінювань працюючих людей та сумісності електричного та електронного технічного обладнання. Розроблено захисні властивості магнітних екранів на основі аморфних сплавів у різних амплітудно-частотних діапазонах. Запропоновано раціональні обгрунтовані рекомендації щодо вибору матеріалу для забезпечення найбільш придатних значень коефіцієнтів екранування Доведено експериментально що аморфні магнітом'які сплави мають сприятливі коефіцієнти екранування від частоти екранованого поля, що підвищує ефективність захисту від магнітних полів працюючих людей та спрощує, з економічної точки зору, обрання матеріалу на конкретному виробництві. Отримані графічні залежності надають можливість обирати необхідний захисний металевий матеріал та автоматизувати процеси розроблення засобів оптимального екранування магнітних полів. Багатосерійність досліджень та легка керованість властивостей матеріалів з різним вмістом металевої субстанції, різної товщини стрічки матеріалу, тощо надає змогу змінювати загальні захисті властивості металевого сплаву ( в залежності від поставленої умови на виробництві).
\end{abstract}

Ключов і слов а: аморфні сплави, електромагнітні поля; коефіцієнт екранування; амплітудно-частотні залежності; захист працюючих; електромагнітна сумісність.

\section{Вступ}

Серед металевих матеріалів для екранування електричних полів найбільш ефективними й перспективними є аморфні магнітом'які сплави.

Їх перевагами $є$ великі магнітні проникності, малі товщини за високих механічних властивостей та стабільність, на відміну від пермалоїв, електрофізичних показників під час експлуатації. При цьому магнітом'які аморфні сплави у достатній кількості виробляються в Україні.

Недоліком аморфних сплавів, як і в усіх металевих матеріалів, є великі коефіцієнти відбиття електромагнітних хвиль, що у багатьох випадках є небажаним через погіршення електромагнітної обстановки у напрямках відбиття.

Але цей показник не завжди критичний, особливо за потреби екранування локалізованих у просторі джерел магнітних полів. При цьому він придатний для одночасного вирішення задач електромагнітної сумісності електричного та електронного обладнання.
Втім, дослідження щодо залежностей коефіцієнтів екранування цих матеріалів від амплітуд та частот екранованих полів мають фрагментарний характер, а похибки вимірювань великі через використання застарілого обладнання.

Тому актуальною є задача максимально коректного вимірювання коефіцієнтів екранування найбільш поширених аморфних магнітом'яких сплавів у залежності від умов їх застосування та надання рекомендацій щодо їх найбільш ефективного використання у галузях охорони праці та електромагнітної сумісності технічних засобів.

Аморфні металеві сплави розроблялися для їх застосування у якості магнітопроводів, мікрозондів тощо, як альтернатива пермалоям, які мають суттєві недоліки - залежність магнітних властивостей від механічних впливів. До того ж розміри виробів 3 аморфних сплавів набагато менші за вироби з електротехнічних сталей та пермалоїв.

Аналіз останніх досліджень і публікацій. Більшість публікацій щодо властивостей таких сплавів мають рекламний характер і стосуються переваг 
конкретних виробів 3 них. У роботах $[1,2]$ було показано, що аморфні магнітом'які сплави можна застосовувати для захисту працюючих. При цьому надано коефіцієнти екранування тільки для деяких частот. Тому, як анонсовано у статтях, дані мають оціночний характер.

У подальшому аморфні сплави використовувалися у прикладних розробках для захисту електрозварювальників та енергетиків, а коефіцієнти екранування магнітного поля промислової частоти визначалися за принципом їх достатності для визначення умов $[3,4]$.

У подальших роботах $[5,6]$ було надано деякі дані щодо залежностей коефіцієнтів екранування аморфних сплавів на основі кобальту від напруженостей та частот магнітних полів, які екрануються. Але, як зазначено у статтях, у якості вимірювачів використовувалося обладнання власної розробки, тому похибки вимірювань складали до 3 дБ. Це неприйнятне у сучасних умовах, коли електромагнітна безпека та електромагнітна сумісність технологічного обладнання є двоєдиною задачею. Тому потребують ретельних досліджень на сучасному обладнанні залежності захисних властивостей аморфних магнітом'яких сплавів від умов їх застосування.

Постановка завдання. Мета роботи - дослідження залежностей коефіцієнтів екранування аморфних магнітом'яких сплавів від амплітудних та частотних характеристик екранованого магнітного поля та надання рекомендацій щодо їх ефективного використання.

\section{Виклад основного матеріалу}

Відомо, що електричне поле легко екранується будь-яким металевим матеріалом, що випливає 3 його фундаментальних властивостей.

В той же час екранування магнітного поля у багатьох випадках є складною задачею і залежить від багатьох технічних характеристик зовнішнього поля, розташування екрану (в залежності від поставленої задачі), різноманітних властивостей екрана (загальних параметрів, складу, товщини тощо), а також - від поставленої загальної мети дослідження та характеристик оточуючого середовища (включаючи інші технічні засоби).

Тому дослідження щодо екрануючих властивостей матеріалів, принаймні у низькочастотній області доцільно виконувати щодо магнітного поля.

Визначення захисних властивостей екранів здійснювалося за методикою [7]. Такий метод полягає у реєстрації спектрів магнітних полів, визначенні критичних амплітуд та їх зниженні у екранованій зоні з урахуванням загальних технічних характеристик та інших критеріїв використання електромагнітних екранів $[8,9]$. Оскільки екранування електромагнітних полів металевими екранами ефективне, дослідження обраних сплавів виконувалося для наднизьких та низьких частот магнітного поля, які впливають на робото спроможність обладнання.

Головні параметри та складові дослідження:

- використовувався сплав на основі кобальту, який виробляється в Україні (ТОВ «Лилта»);
- екрани були суцільними (замкненими), виготовленими плетінням стандартних металевих стрічок товщиною 50 мкм, шириною 0,05 м;

- реєстрація напруженості магнітного поля здійснювалася за допомогою каліброваного аналізатора спектра SPECTRAN NF5035;

- похибка вимірювань не перевищувала $1 \%$.

Результати вимірювань захисних властивостей (коефіцієнтів екранування) наведено на рис. 1 та 2.

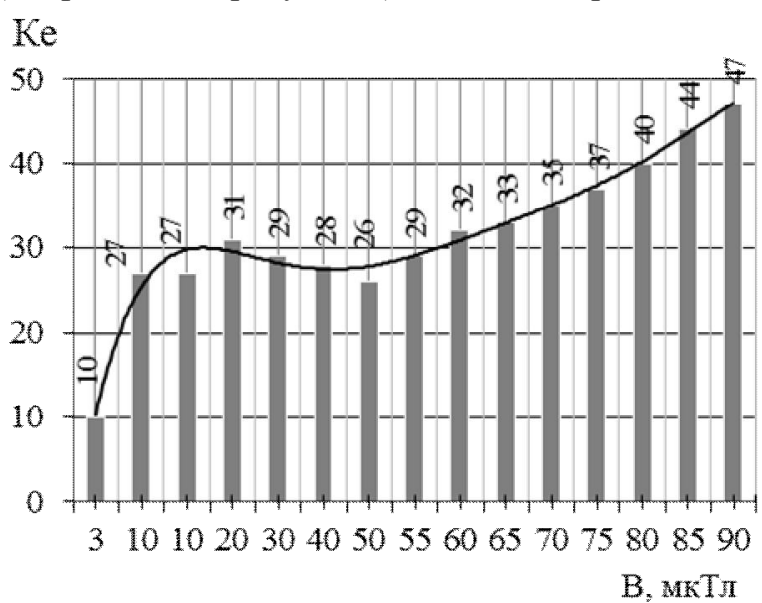

Рис. 1. Залежність коефіцієнта екранування магнітом'яких аморфних сплавів від індукції зовнішнього магнітного поля частотою 50 Гц та 150 Гц (вміст кобальту $70 \%$, товщина екрана 50 мкм)

$\mathrm{K}_{\mathrm{e}}$

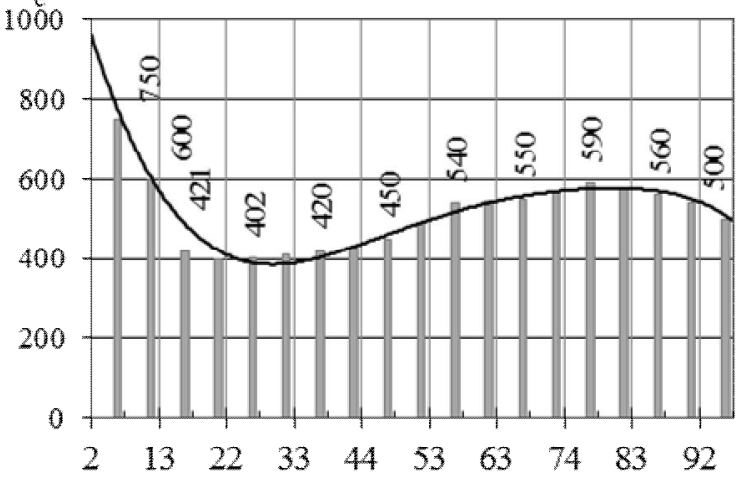

B, MKTI

Рис. 2. Залежність коефіцієнта екранування магнітом' яких аморфних сплавів від індукції зовнішнього магнітного поля частотою 10 кГц (вміст кобальту $70 \%$, товщина екрана 50 мкм)

На основі отриманих залежностей можна зробити висновок про суттєву залежність коефіцієнта екранування від амплітудних значень екранованого поля, що потребує врахування у працеохоронній практиці.

Відомо, що захисні властивості для магнітного поля залежать від магнітної проникності. При використанні аморфних сплавів для підвищення їх магнітних властивостей виконуються термічна та термомагнітна обробка. Термічна обробка виконувалася при температурі $350{ }^{\circ} \mathrm{C}$ упродовж однієї години. Термомагнітна обробка здійснювалася за температури $300{ }^{\circ} \mathrm{C}$ у постійному магнітному полі напруженістю $1000 \mathrm{~A} / \mathrm{M}$. Зміни магнітних властивостей сплавів наведено на рис. 3. 


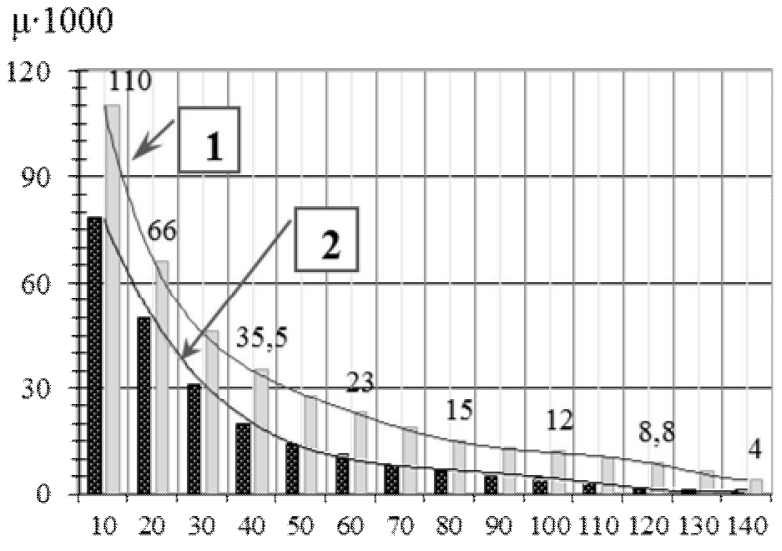

$\checkmark, \mathrm{N} \amalg$

Рис. 3. Залежність магнітної проникності магнітом'якого аморфного сплаву від частоти (вміст кобальту 70 \%): 1 - термооброблений стан, 2 - вихідний стан

Але при цьому спостерігається дуже критична залежність ефективної магнітної проникності від амплітуди екранованого магнітного поля (рис. 4).

$\mu \cdot 1000$

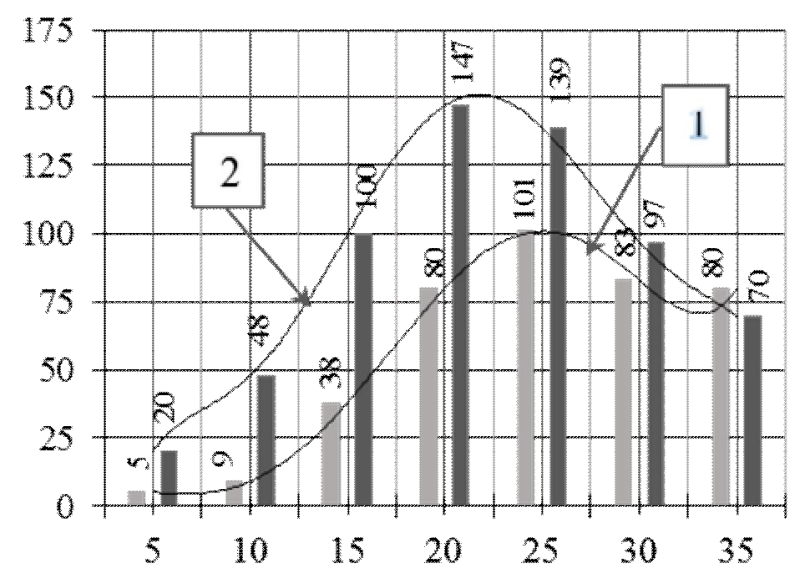

H. A/M

Рис. 4. Залежність магнітної проникності магнітом'якого аморфного сплаву від амплітуди магнітного поля частотою 10 кГц (вміст кобальту $70 \%$ ): 1 - термооброблений стан, 2 - вихідний стан

Було досліджено залежність коефіцієнтів екранування від амплітудних значень магнітного поля (рис. 5 та 6).

Доцільно порівняти магнітні властивості розглянутого аморфного сплаву 3 показниками більш дешевих та поширених пермалоїв (рис. 7).

Наведені дані дозволяють однозначно обрати матеріал для забезпечення потрібних коефіцієнтів екранування магнітного поля і раціоналізувати процес нормалізації електромагнітної обстановки у виробничому середовищі та забезпечити електромагнітну сумісність електронного обладнання на принципах розумної достатності. При цьому слід враховувати, що термічна обробка знижує гнучкість аморфних сплавів.

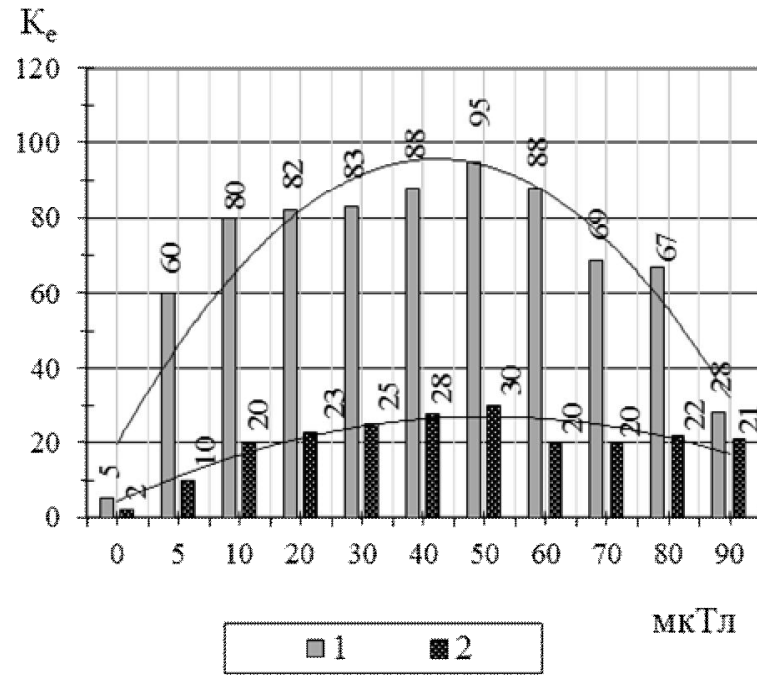

Рис. 5. Залежність захисних властивостей аморфного магнітом'якого сплаву від зміни амплітуди (вміст кобальту $70 \%$, товщина стрічки 50 мкм) на частоті 50-150 Гц; 1- магнітооброблений стан, 2- вихідний стан

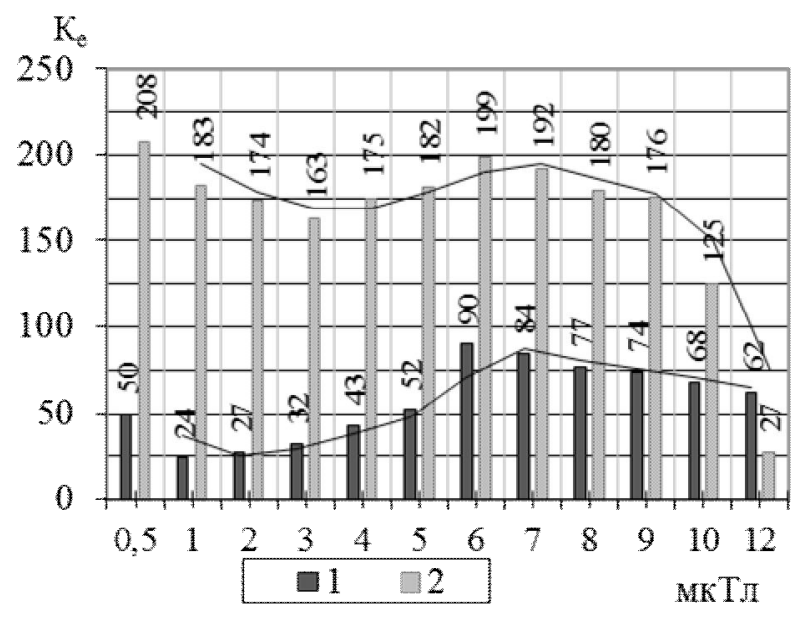

Рис. 6. Залежність захисних властивостей аморфного магнітом'якого сплаву від зміни амплітуди (вміст кобальту $70 \%$, товщина стрічки 50 мкм) на частота 10 кГц; 1- магнітооброблений стан, 2- вихідний стан

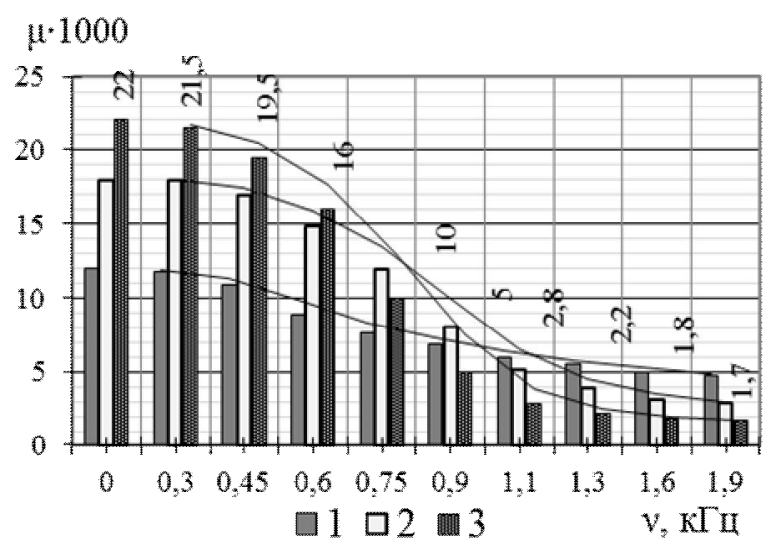

Рис. 7. Залежність магнітних властивостей пермалою від частоти екранованого поля (товщина листа 0,3 мм, 1, 2, 3 - вміст нікелю 79 \%, 68 \%, 80 \% відповідно) 
Аналіз результатів свідчить, що навіть за товщиною, більшою на порядок пермалої поступаються аморфним сплавам. Наведені дані однозначно вказують, що пермалої ефективні тільки на наднизьких і низьких частотах. При цьому їх магнітні властивості дуже різко знижуються зі збільшенням частоти магнітного поля.

\section{Висновки}

1. В усіх металевих матеріалів аморфні сплави найбільш ефективні матеріали для екранування магнітних полів.

2. Аморфні магнітом'які сплави мають більш «гладенькі» залежності коефіцієнтів екранування від частоти екранованого магнітного поля. Це спрощує процес обрання матеріалу у залежності від частотних та амплітудних характеристик магнітного поля.

3. Порівняння захисних властивостей високо кобальтового сплаву у стані заводської поставки, термічною та термомагнітною обробкою свідчить про керованість цих властивостей матеріалу одного хімічного складу.

4. Отримані дані дозволять однозначно обирати стан матеріалу у залежності від умов його застосування та забезпечувати як потрібні рівні захисту працюючих, так і ступені електромагнітної сумісності електронного технологічного обладнання. Це також дає змогу, за використання наведеного графічного матеріалу автоматизувати процеси розроблення засобів оптимального екранування магнітних полів.

\title{
СПИСОК ЛІТЕРАТУРИ
}

1. Levchenko O.G., Levchuk V.K. Safe level of electromagnetic field intensity in resistance. The Paton Welding Journal, 2008. № 5. P. 38-47.

2. Запорожець О.І., Лук'янчиков А.В., Глива В.А. Оцінка захисних властивостей магнітом'яких матеріалів Проблеми охорони прачі в Украӥні, 2007. Вип. 14. С. 35-42.

3. Фартух електрозварника: пат. Україна, МПК G12B17/02; заявл.18.03.1010; опубл. 25.05.2010, Бюл. № 10.

4. Екрануючий комплект: пат. України 90892, МПК G12B 17/00; опубл. 10.06.2014, Бюл. № 11.

5. Панова О.В. Захист працюючих від впливу електромагнітних полів екрануванням: дис. канд. техн. наук: $05.26 .01 /$ Київ, 2014. 151 с.

6. Глива В.А. Забезпечення стабільності функціонування технологічного обладнання в умовах підвищення електромагнітного навантаження на виробниче середовище. Проблеми охорони прайі. 2015. Вип.30. С. 32-36.

7. Спосіб визначення захисних властивостей електромагнітного екрану: пат. України 14984, МПК Е21Д 11/38, G12B 17/00; заяв. 27.12.2012; опубл. 10.06.2013, Бюл. № 11 .

8. Панова О.В. Загальні критерії застосування електромагнітних екранів для забезпечення електромагнітної безпеки та сумісності технічного обладнання. Наука та інноващії. «Вісті Донеиького гірничого інституту», Вип.2(43), 2018, c.11. Режим доступу: www.science.donntu.edu.ua

9. Панова О.В. Екранування електромагнітних полів для електромагнітної безпеки та електромагнітної сумісності обладнання. Управління розвитком складних систем: 3б. наук. працъь. 2015. Вип. № 22. С. 207-213. Режим доступу: http://urss.knuba.edu.ua/files/zbirnyk-22/37.pdf

Received (Надійшла) 29.10.2019

Accepted for publication (Прийнята до друку) 18.12.2019

\author{
Amplitude-frequency dependence research \\ for protective properties of amorphic alloy based magnetic screening \\ V. Glyva, O. Panova, O. Tykhenko, L. Levchenko, V. Kolumbet
}

Abstract. Modern shielding methods offer using metals most suitable for solving several problems simultaneously: protecting workers and electromagnetic compatibility of technical equipment. Amorphous soft magnetic alloys are considered as metallic materials with such properties. The goal of this work is determining protective properties of an amorphous soft magnetic alloy at various frequency and amplitude characteristics, depending on thickness changes of the material tape - magnetic properties of permalloy, depending on various frequencies of the screened field with protective metal material's various percentages of nickel and different values of thickness. Examined the dependence of magnetically soft amorphous alloys' screening coefficient to external magnetic field's induction; the screening coefficients of an amorphous soft magnetic alloy with various percentages of cobalt and different thicknesses to variable amplitude values; the magnetized and initial state (disadvantages and advantages for specific conditions of protective usage considering economic requirements); the magnetically soft amorphous alloy's magnetic permeability dependences for various values of frequency and amplitude. Objective determining the shielding coefficients of protective amorphous soft magnetic alloys for amplitude-frequency characteristics of the shielded magnetic field; substantiation of effectiveness for using such materials and provision of specific recommendations for protection against electromagnetic fields and radiation for working people and compatibility of electrical and electro-technical equipment. Protective properties of magnetic screens based on amorphous alloys in various amplitude-frequency ranges are developed. Unambiguous rational substantiated recommendations for choosing materials to ensure the most suitable values of screening coefficients in this situation are proposed. It has been proven experimentally that amorphous soft magnetic alloys have favorable shielding coefficients, depending on the shielded field's frequency, which increases the efficiency for protecting workers against magnetic fields and simplifies, from an economic point of view, the choice of material in a particular production. The results of graphical dependencies provide the opportunity to choose the necessary protective metal material and automate the development of means of optimal shielding from man-made magnetic fields. Series of studies and easily controlling material properties with different contents of metal substance, different thicknesses of material tape, etc. makes it possible to change the general protective properties of such a metal alloy (depending on the tasks in production).

Keywords : amorphous alloys, electromagnetic fields; shielding factor; amplitude-frequency dependencies; protection of workers; electromagnetic compatibility. 